\title{
Implementasi Metode Forward Chaining dan Certainty Factor Pada Sistem Pakar Diagnosa Osteoporosis
}

\author{
Euis Musyarofah ${ }^{1}$, Rini Mayasari ${ }^{2}$, Agung Susilo Yuda Irawan ${ }^{3}$ \\ 1,2,3Program Studi Teknik Informatika, \\ Fakultas Ilmu Komuter, \\ Universitas Singaperbangsa Karawang, Karawang \\ 1euis.16078@student.unsika.ac.id, ${ }^{2}$ rini.mayasari@staff.unsika.ac.id, \\ 3agung@staff.unsika.ac.id
}

\begin{abstract}
Abstrak
Osteoporosis merupakan salah satu penyakit berisiko pada manusia, terutama pada orang lanjut usia. Penyakit osteoporosis ini tidak hanya menyerang lansia namun bisa menyerang pada orang berusia muda. Hal ini terjadi karena pola makan dan pola hidup seseorang yang tidak teratur. Forward chaining dan certainty factor merupakan salah satu metode dalam sistem pakar. Pada penelitian ini metode Forward chaining merupakan metode cara berfikir sebagai mesin inferensi berdasarkan fakta-fakta yang ada guna mendapatkan suatu kesimpulan serta metode certainty factor digunakan sebagai tolak ukur dari hasil nilai diagnosa terhadap suatu penyakit. Penelitian ini telah berhasil dan tepat menerapkan metode forward chaining dan certainty factor sebagai alat pengambilan keputusan serta tolak ukur pada sistem pakar penyakit osteoporosis.
\end{abstract}

Kata kunci: certainty factor, forward chaining, osteoporosis, sistem pakar.

\begin{abstract}
Osteoporosis is one of the risky diseases for humans, especially the elderly. Yet, osteoporosis not only affects the elderly but also young people. This happens because of a person's irregular diet and lifestyle. Forward chaining and certainty factor is one method in an expert system. In this study, the forward chaining method is a method of thinking as an inference machine based on existing facts in order to get a conclusion, while certainty factors method is used as a measure of the results of the diagnostic value of a disease. This research has been successful and precise in applying the forward chaining method and certainty factors as a decision making tool and benchmark in the osteoporosis expert system.
\end{abstract}

Keywords: certainty factor, forward chaining, osteoporosis, expert system.

\section{Pendahuluan}

Penyakit osteoporosis merupakan masalah kesehatan yang rentan pada orang yang berusia lanjut. Penyakit osteoporosis adalah penyakit yang terjadi ataupun mengiringi proses penuaan pada seseorang yang berakibat pula pada menurunnya masa tulang [1]. Menurut penelitian yang mencatat data statistik penderita gangguan tulang dan sendi yaitu Ministry of Health dan Arthritis Research UK, pada tahun 2015 menyatakan 1 dari 3 
wanita di atas usia 50 tahun akan mengalami patah tulang osteoporosis, seperti halnya 1 dari 5 pria berusia di atas 50 tahun [2].

Salah satu pemanfaatan kemajuan teknologi yakni dalam bentuk implementasi sistem pakar. Sistem pakar atau biasa disebut dengan knowledge base system yaitu suatu aplikasi komputer yang ditunjukkan untuk membantu pengambilan keputusan atau pemecahan persoalan dalam bidang yang spesifik. Sistem ini bekerja dengan menggunakan pengetahuan dan metode analisis yang telah didefinisikan terlebih dahulu oleh pakar yang sesuai dengan bidang keahliannya. Sistem ini disebut sistem pakar karena fungsi dan perannya sama seperti seorang ahli yang harus memiliki pengetahuan, pengalaman dalam memecahkan suatu persoalan. Sistem biasanya berfungsi sebagai kunci penting yang akan membantu suatu sistem pendukung keputusan atau sistem pendukung eksekutif [3].

Sebelumnya telah dilakukan penelitian untuk diagnosa penyakit dan hama tanaman cabai dengan metode forward chaining. Hasil dari penelitian yang telah dilakukan yaitu penerapan metode forward chaining ini memudahkan dalam memberikan informasi berupa kesimpulan tentang penyakit tanaman cabai sehingga hal ini bisa menjadi acuan [4]. Penelitian lainnya menggunakan metode certainty factor sebagai nilai uji tingkat keakurasian diagnosa secara manual maupun sistem. Hasil dari penelitian tersebut yaitu berupa kesesuaian identifikasi jenis kulit wajah pada sistem pakar dengan pakar kulit yaitu dengan tingkat akurasi sebesar 91\%, sehingga sistem dapat membantu user untuk mengetahui jenis kulit wajah agar mendapatkan perawatan yang sesuai [5].

Sistem pakar ini diimplementasikan menggunakan metode forward chaining karena merupakan metode cara berfikir untuk memperoleh kesimpulan dengan melakukan penalaran berdasarkan fakta-fakta yang ada guna mendapatkan suatu kesimpulan serta metode certainty factor yang digunakan sebagai tolak ukur dari hasil nilai diagnosa terhadap suatu penyakit. Tujuan dari penerapan metode forward chaining dan certainty factor dalam sistem pakar diagnosis penyakit osteoporosis ini adalah untuk memberikan informasi serta mendiagnosa penyakit osteoporosis dengan hasil dari metode certainty factor sebagai tolak ukur seberapa besar peluang terkena osteoporosis.

\section{Tinjauan Pustaka}

\subsection{Sistem Pakar}

Sistem pakar merupakan sebuah aplikasi komputer yang bertujuan untuk membantu dalam pengambilan keputusan atau pemecahan masalah dalam bidang spesifik yang fungsi dan perannya sama seperti seorang ahli atau pakar yang harus memiliki pengetahuan, pengalaman dalam memecahkan masalah [3]. Sistem pakar merupakan sistem komputer yang memanfaatkan secara maksimal pengetahuan khusus selayaknya seorang pakar dalam memecahkan masalah [6].

\subsection{Forward Chaining}

Forward chaining adalah teknik pencarian yang dimulai dengan fakta yang diketahui kemudian mencocokkan fakta-fakta tersebut dengan IF dari rule IF-THEN. Bila ada fakta yang cocok dengan bagian IF maka rule tersebut dieksekusi. Bila sebuah rule dieksekusi maka sebuah fakta baru (bagian THEN) ditambahkan ke dalam database. Dimulai dari rule teratas setiap kali pencocokan dan setiap rule hanya boleh dieksekusi satu kali saja. Proses pencocokan berhenti bila tidak ada lagi rule yang bisa dieksekusi [7]. Bentuk 
representasi rule-based reasoning digunakan karena memiliki sejumlah pengetahuan pakar pada suatu permasalahan tertentu dan pakar dapat menyelesaikan masalah tersebut secara sistematis dan berurutan [8].

\subsection{Certainty Factor}

Metode certainty factor menunjukkan ukuran kepastian terhadap suatu fakta atau aturan. Certainty factor merupakan nilai parameter klinis yang diberikan MYCIN untuk menunjukkan besarnya kepercayaan [9],[10]. Kelebihan dari metode certainty factor adalah dapat mengukur sesuatu yang pasti atau tidak pasti dalam pengambilan keputusan pada sistem pakar diagnosa penyakit [11],[12]. Rumus dasar certainty factor ditunjukkan pada Persamaan (1)[13].

$$
\mathrm{CF}(h, e)=\mathrm{MB}(h, e)-\mathrm{MD}(h, e)
$$

Keterangan :

$$
\begin{aligned}
\mathrm{CF}(h, e)= & \text { Certainty Factor (faktor kepastian) dalam hipotesis } h \text { dipengaruhi oleh } \\
& \text { evidence (gejala) } e . \\
\mathrm{MB}(h, e)= & \text { Measure of Belief (tingkat keyakinan), merupakan ukuran kepercayaan dari } \\
& \text { hipotesis } h \text { dipengaruhi oleh evidence (gejala) } e . \\
\mathrm{MD}(h, e)= & \text { Measure of Disbelief (tingkat ketidakyakinan), merupakan ukuran ketidak- } \\
& \text { percayaan dari hipotesis } h \text { dipengaruhi oleh gejala } e . \\
= & \text { Hipotesa atau konklusi yang dihasilkan (antara } 0 \text { dan } 1) . \\
= & \text { Evidence atau peristiwa atau fakta (gejala). }
\end{aligned}
$$

Perhitungan selanjutnya adalah kombinasi dua atau lebih rule dengan evidence berbeda tetapi dalam hipotesis yang sama, yang ditunjukkan pada Persamaan (2) - (4).

$$
\begin{gathered}
\text { Rule } 1 \mathrm{CF}\left(h, e_{1}\right)=\mathrm{CF}_{1}=\mathrm{C}\left(e_{1}\right) \times \mathrm{CF}\left(\text { Rule }_{1}\right) \\
\text { Rule } 2 \mathrm{CF}\left(h, e_{2}\right)=\mathrm{CF}_{2}=\mathrm{C}\left(e_{2}\right) \times \mathrm{CF}\left(\text { Rule }_{2}\right) \\
\mathrm{CF} \text { Kombinasi }\left(\mathrm{CF}_{1}, \mathrm{CF}_{2}\right)=\mathrm{CF}_{1}+\mathrm{CF}_{2}\left(1-\mathrm{CF}_{1}\right)
\end{gathered}
$$

\subsection{Osteoporosis}

Osteoporosis berasal dari kata osteo dan porous, osteo berarti tulang serta porous artinya berlubang-lubang atau keropos. Selain faktor berkurangnya massa tulang, penyebab lain dari Osteoporosis adalah mengonsumsi beberapa macam obat-obatan dalam jangka panjang yang dapat merusak tulang seperti obat anti kejang dan hormon tiroid yang diresepkan dalam dosis tinggi, dan terganggunya proses penyerapan kalsium, serta cushing yaitu produksi kortisol tubuh yang berlebihan [1],[14]. Beberapa kondisi berikut dapat menjadi gejala terjadinya osteoporosis, yaitu sakit punggung, postur tubuh bungkuk, menurunnya tinggi badan, lebih sering mengalami cedera/keretakan tulang, berkurangnya kepadatan dapat membuat tulang rentan untuk retak, keretakan biasanya terjadi pada tulang belakang, pergelangan tangan, lengan, atau tulang pangkal paha. 


\section{Metodologi}

Dalam pembuatan sistem pakar ini, metode pengembangan sistem pakar yang digunakan adalah Expert System Development Life Cycle (ESDLC) [15]. Metode ini dipilih dengan alasan model pengembangan menggunakan tahapan yang dapat merepresentasikan kebutuhan pada pembuatan sistem pakar untuk diagnosis penyakit osteoporosis berdasarkan gejala yang dimasukkan. Gambar 1 menjelaskan tahapantahapan yang terdapat dalam Expert System Development Life Cycle (ESDLC) :

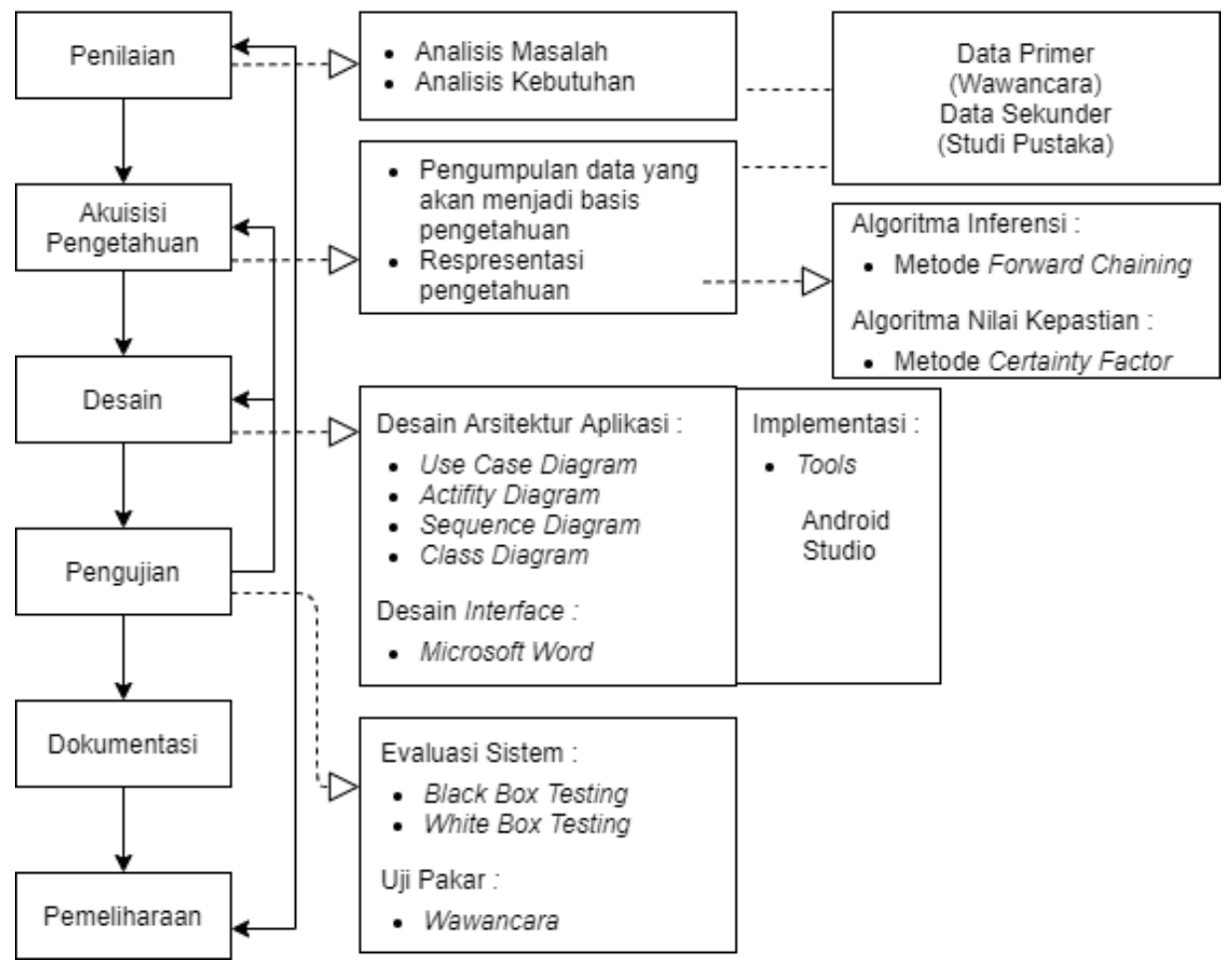

Gambar 1. Tahapan-tahapan ESDLC

\section{Hasil dan Pembahasan}

\subsection{Penilaian}

Tahap ini merupakan tahap untuk mengkaji dan membatasi masalah yang akan diimplementasikan dalam sistem [16]. Tahapan ini penting untuk tahapan selanjutnya, karena kesalahan maupun kekurangan pada tahapan ini akan mempengaruhi tahapan selanjutnya. Tahap penilaian yang dilakukan adalah analisis permasalahan. Berdasarkan hasil wawancara dengan seorang pakar dan didapatkan hasil analisis permasalahan yang dapat disimpulkan sebagai berikut :

1. Kurangnya pengetahuan dari pasien tentang penyakit osteoporosis

2. Solusi dalam mengenai penyakit osteoporosis

3. Biaya yang dibutuhkan ketika berobat terlalu mahal

\subsection{Akuisisi Pengetahuan}

Pada tahap ini bertujuan untuk mengakuisisi pengetahuan pakar ke dalam sistem, di mana dilakukan dua tahapan dalam pelaksanaannya, yaitu antara lain : 


\subsubsection{Pengumpulan data}

Pada tahap pengumpulan data, ada dua teknik yang digunakan untuk memperoleh pengetahuan yang dibutuhkan oleh sistem pakar diagnosa penyakit osteoporosis ini yaitu :

1. Data primer dilakukan dengan wawancara langsung kepada pakar. Wawancara dilakukan dengan melakukan tanya jawab dengan pihak terkait (dokter) untuk mendapatkan informasi yang dibutuhkan dalam proses pembuatan dan pengembangan aplikasi.

2. Data sekunder dilakukan dengan studi pustaka untuk memperoleh pengetahuan dengan membaca literatur yang berhubungan dengan penelitian ini. Setelah mendapatkan referensi yang relevan kemudian mencari informasi-informasi yang dibutuhkan dalam penelitian. Informasi yang didapat digunakan dalam penyusunan landasan teori, metodologi penelitian serta pembuatan aplikasi.

Hasil dari pengumpulan data yang telah dilakukan tersebut akan ditampilkan berupa kode " $\mathrm{P}$ " yang berarti jenis penyakit dan kode " $\mathrm{G}$ " yang berarti gejala dari penyakit osteoporosis serta relasi antar gejala dengan penyakit. Tabel 1 menjelaskan jenis dari penyakit osteoporosis, sementara Tabel 2 menjelaskan jenis gejala penyakit osteoporosis dan Tabel 3 menjelaskan relasi penyakit dan gejala osteoporosis.

Tabel 1. Jenis Penyakit

\begin{tabular}{|c|c|c|}
\hline No & Kode & Penyakit Osteoporosis \\
\hline 1 & P01 & Bukan Osteoporosis \\
\hline 2 & P02 & Osteoporosis Primer \\
\hline 3 & P03 & Osteoporosis Sekunder \\
\hline 4 & P04 & Osteoporosis Idiopatik \\
\hline
\end{tabular}

Tabel 2. Gejala Penyakit Osteoporosis

\begin{tabular}{|c|l|l|}
\hline No & Kode & \multicolumn{1}{|c|}{ Penyakit Osteoporosis } \\
\hline 1 & G01 & Usia lebih dari 40 tahun \\
\hline 2 & G02 & Kelebihan berat badan \\
\hline 3 & G03 & Memiliki riwayat patah tulang \\
\hline 4 & G04 & $\begin{array}{l}\text { Memiliki riwayat penyakit anggota keluarga } \\
\text { yang mengidap osteoporosis }\end{array}$ \\
\hline 5 & G05 & Mengalami manopause \\
\hline 6 & G06 & Merasakan sakit punggung berkelanjutan \\
\hline 7 & G07 & Sering merokok \\
\hline 8 & G08 & Nyeri pada sendi \\
\hline 9 & G09 & Kekurangan hormon testoteron \\
\hline 10 & G010 & Sering konsumsi minuman keras \\
\hline 11 & G011 & Keretakan pada tulang punggung \\
\hline 12 & G012 & $\begin{array}{l}\text { Konsumsi obat-obatan golongan steroid } \\
\text { seperti Glukokortikoid }\end{array}$ \\
\hline 13 & G013 & Mengidap penyakit hipertiroidisme \\
\hline
\end{tabular}

Tabel 3. Relasi Gejala dan Penyakit Osteoporosis

\begin{tabular}{|c|c|c|c|c|}
\hline \multirow{2}{*}{ No } & \multirow{2}{*}{ Kode } & \multicolumn{3}{|c|}{ Penyakit } \\
\cline { 3 - 5 } & & P1 & P2 & P3 \\
\hline 1 & G01 & $*$ & $*$ & \\
\hline 2 & G02 & $*$ & $*$ & \\
\hline 3 & G03 & $*$ & $*$ & \\
\hline 4 & G04 & & & $*$ \\
\hline 5 & G05 & $*$ & & $*$ \\
\hline
\end{tabular}




\begin{tabular}{|c|c|c|c|c|}
\hline 6 & G06 & & & $*$ \\
\hline 7 & G07 & & $*$ & \\
\hline 8 & G08 & $*$ & $*$ & $*$ \\
\hline 9 & G09 & & & $*$ \\
\hline 10 & G010 & & $*$ & \\
\hline 11 & G011 & $*$ & & $*$ \\
\hline 12 & G012 & & $*$ & \\
\hline 13 & G013 & $*$ & $*$ & \\
\hline
\end{tabular}

\subsubsection{Representasi Pengetahuan}

Teknik representasi pengetahuan dalam sistem pakar identifikasi penyakit osteoporosis adalah dengan menggunakan kaidah produksi. Representasi pengetahuan dengan kaidah produksi sebagai kaidah aturan (rule) yang berupa IF (kondisi/premis) THEN (aksi/kesimpulan) di mana kondisi merupakan bagian awal yang mengekspresikan situasi premis (pernyataan berawal IF) dan aksi merupakan bagian yang menyatakan suatu tindakan tertentu atau kondisi yang diharapkan jika suatu situasi atau premis bernilai benar (pernyataan berawalan THEN). Tabel 4 menjelaskan rule pada penyakit osteoporosis.

Tabel 4. Rule Penyakit Osteoporosis
\begin{tabular}{|c|c|}
\hline No & Kaidah Produksi \\
\hline 1 & IF G01 and G02 and G03 and G05 and G08 and G11 and G13 THEN P01 \\
\hline 2 & IF G0 and G02 and G03 and G07 and G08 and G10 and G12 and G13 THEN P02 \\
\hline 3 & IF G04 and G05 and G06 and G08 and G09 and G11 THEN P03 \\
\hline
\end{tabular}

Selain kaidah produksi, representasi pengetahuan juga dibuat dalam bentuk diagram pohon (tree). Diagram ini menggambarkan pertanyaan gejala yang ditampilkan oleh sistem untuk menghasilkan sebuah kesimpulan atau keputusan. Jika user menjawab "tidak" pohon akan menuju ke cabang kanan, seperti ditunjukkan Gambar 2 :

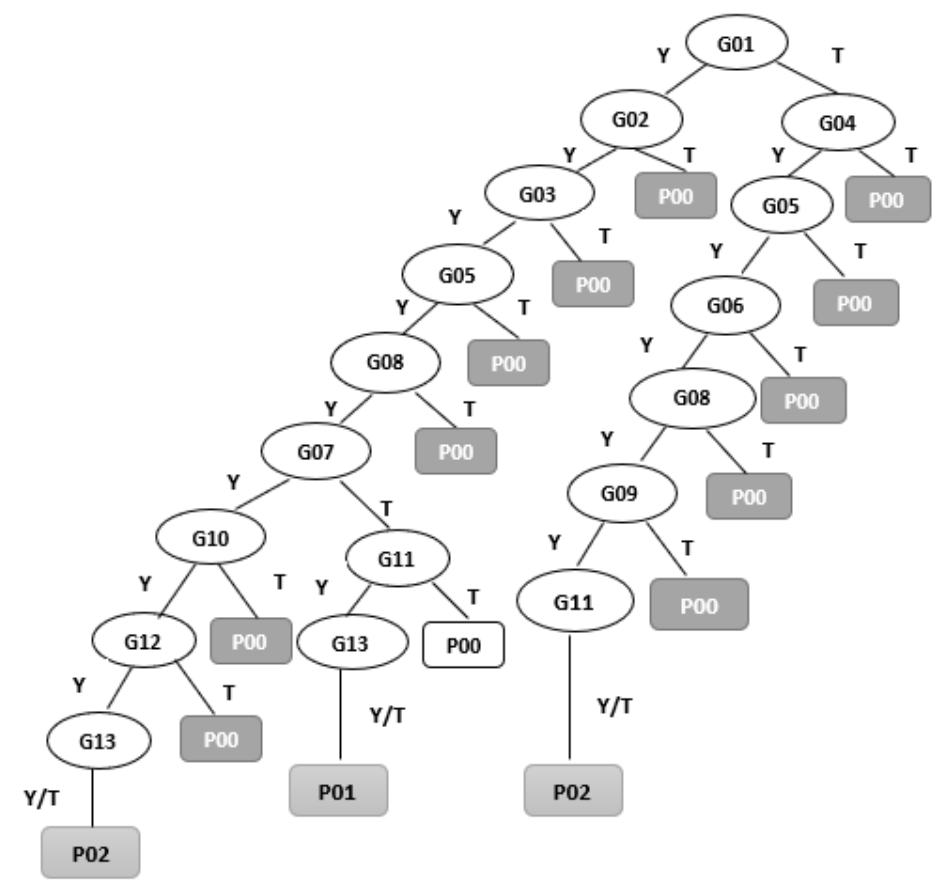

Gambar 2. Diagram Pohon 


\subsubsection{Metode Certainty Factor}

Dalam mengekspresikan derajat keyakinan digunakan suatu nilai yang disebut nilai kepastian atau certainty factor (CF) untuk mengansumsikan derajat keyakinan seorang pakar terhadap suatu data. Berikut adalah tahapan-tahapan untuk perhitungan nilai CF dari masing-masing penyakit :

1. Menentukan nilai bobot MB dan MD

Tahapan pertama yaitu menentukan nilai bobot MB dan MD yang diperoleh dari seorang pakar, di mana nilai MB merupakan bobot nilai yang mempunyai tingkat keyakinan setiap gejala dari masing-masing penyakit, sedangkan nilai MD merupakan nilai ketidakyakinan setiap gejala dari masing-masing penyakit. Tabel 5 ini menjelaskan nilai $\mathrm{MB}$ dan MD dari masing-masing gejala pada penyakit Osteoporosis.

Tabel 5. Nilai bobot MB dan MD

\begin{tabular}{|c|c|c|c|}
\hline No & Kode & Nilai MB & Nilai MD \\
\hline 1 & G1 & 0,7 & 0,2 \\
\hline 2 & G2 & 0,6 & 0,3 \\
\hline 3 & G3 & 0,6 & 0,1 \\
\hline 4 & G4 & 1 & 0,1 \\
\hline 5 & G5 & 0,6 & 0,3 \\
\hline 6 & G6 & 0,7 & 0,2 \\
\hline 7 & G7 & 0,8 & 0,1 \\
\hline 8 & G8 & 0,6 & 0,2 \\
\hline 9 & G9 & 0,7 & 0,2 \\
\hline 10 & G10 & 0,8 & 0,1 \\
\hline 11 & G11 & 0,6 & 0,2 \\
\hline 12 & G12 & 0,7 & 0,1 \\
\hline 13 & G13 & 0,6 & 0,2 \\
\hline
\end{tabular}

2. Menghitung nilai CF dari masing-masing gejala

Pada Tabel 6 menjelaskan hasil perhitungan nilai CF menggunakan rumus dasar certainty factor yang ditunjukkan pada Persamaan (1).

Tabel 6. Nilai bobot MB dan MD
\begin{tabular}{|c|c|c|}
\hline No & Kode & Nilai CF $=$ MB- MD \\
\hline 1 & G1 & 0,5 \\
\hline 2 & G2 & 0,3 \\
\hline 3 & G3 & 0,5 \\
\hline 4 & G4 & 0,9 \\
\hline 5 & G5 & 0,3 \\
\hline 6 & G6 & 0,5 \\
\hline 7 & G7 & 0,7 \\
\hline 8 & G8 & 0,4 \\
\hline 9 & G9 & 0,5 \\
\hline 10 & G10 & 0,7 \\
\hline 11 & G11 & 0,4 \\
\hline 12 & G12 & 0,6 \\
\hline 13 & G13 & 0,4 \\
\hline
\end{tabular}

3. Menghitung nilai CF kombinasi dari masing-masing penyakit

Tahap selanjutnya adalah proses perhitungan CF kombinasi yang nantinya akan mendapatkan hasil nilai tingkat kepercayaan pada masing-masing penyakit. Perhitungan 
ini menggunakan rumus CF kombinasi yang ditunjukkan pada persamaan (4). Berikut contoh perhitungan $\mathrm{CF}$ kombinasi pada penyakit osteoporosis primer :

CF Kombinasi $\left(\mathrm{CF}_{1}, \mathrm{CF}_{2}\right)=\mathrm{CF}_{1}+\mathrm{CF}_{2}\left(1-\mathrm{CF}_{1}\right)$

$=0,5+0,3 *(1-0,5)$

$=0,5+0,3 *(0,5)$

$=0,5+0,15$

$=0,65$

CF Kombinasi $\left(\mathrm{CF}_{2}, \mathrm{CF}_{3}\right)=\mathrm{CF}_{2}+\mathrm{CF}_{3}\left(1-\mathrm{CF}_{2}\right)$

$=0,65+0,5 *(1-0,65)$

$=0,65+0,5 *(0,35)$

$=0,65+0,175$

$=0,825$

CF Kombinasi $\left(\mathrm{CF}_{3}, \mathrm{CF}_{4}\right)=\mathrm{CF}_{3}+\mathrm{CF}_{4}\left(1-\mathrm{CF}_{3}\right)$

$=0,825+0,3 *(1-0,825)$

$=0,825+0,3 *(0,175)$

$=0,825+0,525$

$=0,8775$

CF Kombinasi $\left(\mathrm{CF}_{4}, \mathrm{CF}_{5}\right)=\mathrm{CF}_{4}+\mathrm{CF}_{5}\left(1-\mathrm{CF}_{4}\right)$

$=0,8775+0,4 *(1-0,8775)$

$=0,8775+0,4 *(0,1225)$

$=0,8775+0,049$

$=0,9265$

CF Kombinasi $\left(\mathrm{CF}_{5}, \mathrm{CF}_{6}\right)=\mathrm{CF}_{5}+\mathrm{CF}_{6}\left(1-\mathrm{CF}_{5}\right)$

$=0,9265+0,4 *(1-0,9265)$

$=0,9265+0,4 *(0,735)$

$=0,9265+0,0294$

$=0,9559$

CF Kombinasi $\left(\mathrm{CF}_{6}, \mathrm{CF}_{7}\right)=\mathrm{CF}_{6}+\mathrm{CF}_{7}\left(1-\mathrm{CF}_{6}\right)$

$=0,9559+0,4 *(1-0,9559)$

$=0,9559+0,4 *(0,0441)$

$=0,9559+0,01764$

$=0,97354$

Dari hasil perhitungan di atas dapat diketahui bahwa tingkat kepercayaan dari hasil diagnosa terhadap penyakit osteoporosis primer sebesar 0,97354 atau 0,97\%.

\subsection{Desain}

Tahapan desain ini merupakan tahapan perancangan pembangunan perangkat lunak dan proses-prosesnya menggunakan pemodelan UML. Gambar 3 menunjukkan use case diagram sistem yang menjelaskan mengenai proses berjalannya sistem. 


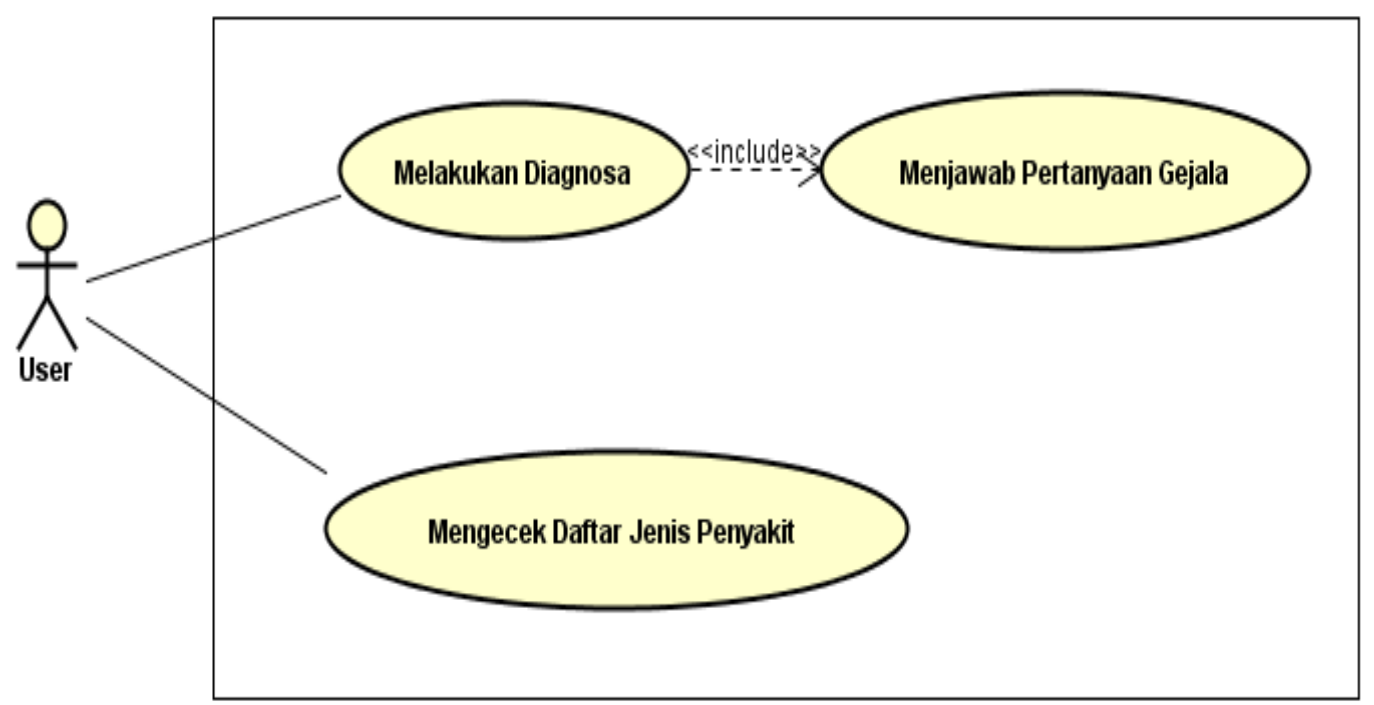

Gambar 3. Use case diagram

\subsection{Pengujian}

Pada tahap ini akan dilakukan pengujian. Pengujian dibagi menjadi dua yaitu pengujian sistem dengan menggunakan black box testing serta melakukan pengujian pakar.

\section{Black Box Testing}

Black box testing atau pengujian kotak hitam dilakukan dengan membuat kasus uji yang bersifat mencoba semua fungsi dan memakai perangkat lunak apakah sesuai dengan spesifikasi yang dibutuhkan. Kasus uji yang dibuat untuk melakukan pengujian kotak hitam harus dibuat dengan kasus benar dan kasus salah [17]. Tabel 7 menjelaskan tentang pengujian black box testing pada menu utama.

Tabel 7. Pengujian Black Box Testing pada Menu Utama

\begin{tabular}{|c|l|l|c|c|}
\hline No & \multicolumn{1}{|c|}{ Data Masukan } & \multicolumn{1}{|c|}{ Hasil yang diharapkan } & Respon Sistem & Hasil Uji \\
\hline 1 & Menampilkan Halaman & $\begin{array}{l}\text { Sistem menampilkan halaman } \\
\text { yang berisi button-button. }\end{array}$ & $\begin{array}{c}\text { Sesuai } \\
\text { harapan }\end{array}$ & Diterima \\
& Utama & Sistem menampilkan menu & $\begin{array}{c}\text { Sesuai } \\
\text { harapan }\end{array}$ & Diterima \\
\hline 2 & Memilih Menu & diagnosis & $\begin{array}{c}\text { Sesuai } \\
\text { harapan }\end{array}$ & Diterima \\
& Melakukan Diagnosis & Memilih Menu Mengecek & $\begin{array}{l}\text { Sistem menampilkan menu } \\
\text { daftar penyakit }\end{array}$ & \\
\hline
\end{tabular}

\section{Uji Pakar}

Pengujian dengan pakar sangat penting dalam pembuatan aplikasi sistem pakar, yang berfungsi untuk menvalidasi hasil penelitian yang telah dilakukan. Apakah masukan serta keluaran yang ditampilkan oleh sistem sesuai dengan aturan pengetahuan pakar. Hasil akhir dari aplikasi diagnosis penyakit osteoporosis berupa persentasi tingkat keyakinan pada sebuah penyakit osteoporosis yang diderita. Pengujian pakar pada penelitian ini dilakukan dengan seorang dokter spesialis Orthopedi guna diagnosa penyakit osteoporosis yang dihasilkan tepat dan sesuai. Tabel 8 berikut adalah hasil uji pakar. 
Tabel 8. Uji Pakar

\begin{tabular}{|c|l|c|c|}
\hline No & \multicolumn{1}{|c|}{ Gejala } & $\begin{array}{c}\text { Kesimpulan } \\
\text { Sistem }\end{array}$ & $\begin{array}{c}\text { Kesimpulan } \\
\text { Pakar }\end{array}$ \\
\hline 1 & $\begin{array}{l}\text { IF G01 and G02 and G03 and G05 and G08 and G11 } \\
\text { and G13 }\end{array}$ & P01 & Sesuai \\
\hline 2 & $\begin{array}{l}\text { IF G0 and G02 and G03 and G07 and G08 and G10 } \\
\text { and G12 and G13 }\end{array}$ & P02 & Sesuai \\
\hline 3 & IF G04 and G05 and G06 and G08 and G09 and G11 & P03 & Sesuai \\
\hline
\end{tabular}

\subsection{Dokumentasi}

Pendokumentasian ini meliputi cara pengopreasian sistem. Dalam proses pengoperasian sistem user atau pengguna dapat menggunakan beberapa menu yang ada di dalam sistem. Gambar 4 menjelaskan kesimpulan hasil diagnosa yang dilakukan user dengan menjawab pertanyaan tentang gejala yang dialami oleh $u s e r$.

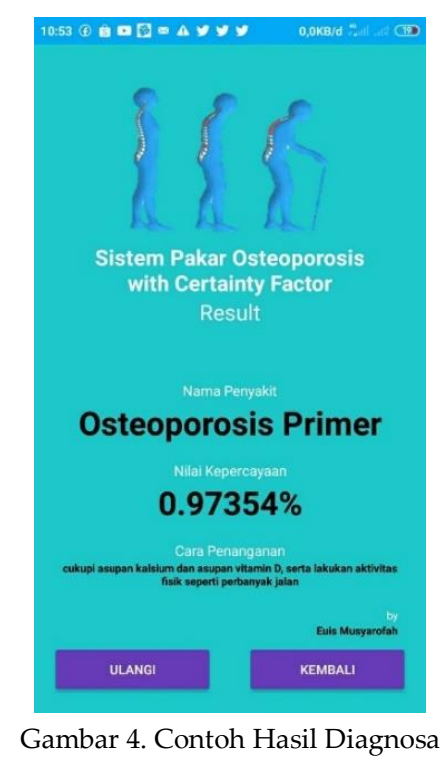

\subsection{Pemeliharaan}

Tahap pemeliharaan merupakan tahapan akhir dari metode ESDLC (Expert System Development Life Cycle). Apabila terdapat jenis penyakit atau gejala baru yang muncul pada penyakit osteoporosis maka sistem pakar akan di-update untuk menyempurnakan sistem pakar yang telah dibuat untuk memenuhi kebutuhan penggunanya.

\section{Kesimpulan}

Berdasarkan penelitian yang telah dilakukan, maka dapat diambil kesimpulan yakni penggunaan metode forward chaining digunakan untuk memperoleh kesimpulan dengan melakukan penalaran dari suatu masalah kepada solusinya dan metode certainty factor dapat memberikan hasil tingkat keyaninan yang tinggi. User melakukan diagnosa dengan cara menginputkan beberapa gejala kemudian sistem memberikan hasil informasi penyakit, nilai kepercayaan dan cara penanganannya. Penerapan sistem pakar diagnosa penyakit osteoporosis dengan memasukkan penalaran seorang pakar dapat dilakukan sistem. Sehingga user dapat menjawab pertanyaan-pertanyaan yang ditampilkan sistem dan sistem dapat hasil yang sesuai dengan rule yang sudah dimasukkan. 


\section{Daftar Pustaka}

[1] Yuhandri, "Diagnosia penyakit osteoporosis menggunakan metode certainty factor," Jurnal Resti, Vol. 2, no.1, pp. 422-429, 2018.

[2] Ministry of Health, "World Osteoporosis Day 2015," [online], https://www.moh.gov.sa/en/HealthAwareness/healthDay/2015/Pages/HealthDay2015-10-20.aspx, diakses 21 agustus 2020.

[3] H. B. Herawan, Sistem Pakar, Yogyakarta, Depublish, 2018.

[4] M. A. Fitriani dan C. Febrianto, "Penerapan sistem pakar untuk diagnosa penyakit dan hama tanaman cabai dengan metode forward chaining," Sainteks, vol. 16, no. 2, 2019.

[5] Y. K. Kumarahadi, M. Z. Arifin, S. Pambudi, T. Prabowo, dan Kusrini, “Sistem pakar identifikasi jenis kulit wajah dengan metode certainty factor," Jurnal Tikomsin, vol. 8, no. 1, 2018.

[6] R. Rosnelly, "Sistem Pakar Konsep dan Teori," Yogyakarta, ANDI, 2012.

[7] P. S. Ramadhan dan U. F. S. Pane, "Mengenal Metode Sistem Pakar," Ponorogo, Uwais Inspirasi Indonesia, 2018.

[8] N. Susilo, A. Riyadi, dan M. Fairuzabadi, " Sistem pakar diagnosa penyakit gigi dan mulut menggunakan metode forward chaining berbasis web," Prosiding Seminar Dinamika Informatika (SENADI), 2018.

[9] R. D. Heriyanto dan H. Leidiyana, "Sistem pakar mendiagnosa penyakit persendian menggunakan metode certainty factor," Jurnal Komtika (Komputasi dan Informatika), vol. 4, no.1, 2020.

[10] L. Septiana, "Perancangan sistem pakar diagnosa penyakit ISPA dengan metode certainty factor berbasis Android," Jurnal Tecno Nusa Mandiri, vol. 13, no.2, 2016.

[11]K. E. Setyaputri, A. Fadlil, dan Sunardi, "Analisis metode certainty factor pada sistem pakar diagnosa penyakit THT," Jurnal Teknik Elektro, vol. 10, no. 1, 2018.

[12] E. Mulyanto dan V. Suhartono, Kecerdasan Buatan, Yogyakarta: Andi, 2010.

[13] Kusrini, “Aplikasi Sistem Pakar" Yogyakarta, 2008, Andi.

[14]H. Tandra, "Segala Sesuatu Yang Harus Anda Ketahui Tentang Osteoporosis Mengenal, Mengatasi, dan Mencegah," Jakarta, Gramedia Pustaka Utama, 2009.

[15] M.P. Sari, Realize, "Sistem Pakar Mendiagnosa Penyakit Osteoporosis Pada Lansia Menggunakan Metode Forward Chaining Berbasis Web," Jurnal Ilmiah Informatika(JIF), vol.07, no.01, 2019.

[16]S. Kusumadewi, Artificial Intelligence (Teknik dan Aplikasinya), Yogyakarta, Graha Ilmu, 2003.

[17]R.A.Sukamto dan M. Shalahuddin, Modul Pembelajaran Rekayasa Perangkat Lunak (Terstruktur dan Berorientasi Objek), Bandung, Modula, 2015. 
